\title{
Epidemiological Aspects of Stroke in Young People at the Friendship University Hospital Center in Bangui in the Central African Republic
}

\author{
Emmanuel Yangatimbi1,2, Junior Koma Zobanga ${ }^{2}$, Symphorien Shansy Grégbia², Josué Kinima², \\ Pascal Mbelesso ${ }^{1,2}$
}

${ }^{1}$ Department of Neurology, University Hospital of the Sino-Central African Friendship, Bangui, Central African Republic ${ }^{2}$ Faculty of Health Sciences, University of Bangui, Bangui, Central African Republic

Email: yang_emma1@yahoo.fr

How to cite this paper: Yangatimbi, E., Zobanga, J.K., Grégbia, S.S., Kinima, J. and Mbelesso, P. (2020) Epidemiological Aspects of Stroke in Young People at the Friendship University Hospital Center in Bangui in the Central African Republic. Neuroscience \& Medicine, 11, 91-99. https://doi.org/10.4236/nm.2020.114011

Received: July 3, 2020

Accepted: October 9, 2020

Published: October 12, 2020

Copyright $\odot 2020$ by author(s) and Scientific Research Publishing Inc. This work is licensed under the Creative Commons Attribution International License (CC BY 4.0).

http://creativecommons.org/licenses/by/4.0/

\section{(c) (i) Open Access}

\begin{abstract}
Introduction: Stroke is a major public health problem even more dramatic in young people. Goal of the study: To make our contribution to the knowledge of strokes of the young subject. Methodology: It was a retrospective study conducted over a period of 02 years (January 2017 to December 2018) including the files of patients aged 18 to 49 years hospitalized for any suspected case of stroke in the Department of Neurology of C between Hospitalier A Sino-Central African Friendship University (CHUSCA) from Bangui. Results: During the study, 225 cases of stroke were recorded, including 26 cases in young subjects, representing a hospital frequency of $11.5 \%$. The average age was 42.5 years with extremes ranging from 24 to 49 years. The most represented age group was 45 and 49 with a sex ratio (M/F) of 1.36. The average age for men was 41.93 years compared to 39.27 years for women. Civil servants were in the majority in $50 \%$ of the cases. Alcohol was the main FDR (80.8\%) followed by hypertension (61.5\%) and tobacco (50\%). The majority of patients $(57.70 \%)$ were admitted to neurology after the first 24 hours. Ischemic stroke represented $73.08 \%$ compared to $26.92 \%$ of AVCH. The lethality was $20.08 \%$. The sequelae were found in $69.20 \%$ of cases. Cardiac exploration had found $57.10 \%$ of LVH. Conclusion: This study confirms a high frequency of stroke in the young subject. The predominance of modifiable FRCVs requires the implementation of a specific strategy based on awareness, early detection and effective and adequate PEC.
\end{abstract}

\section{Keywords}

Stroke, Young Subject, Bangui Central African Republic 


\section{Introduction}

Stroke is a real public health problem. Each year, around fifteen million people suffer from it worldwide, of which five million die and another five million suffer from permanent disabilities [1] [2]. In developing countries (PVD), they represent the second leading cause of death, behind cardiovascular diseases, ahead of infectious diseases, in particular pulmonary or diarrheal infections, tuberculosis, AIDS or malaria and more than $80 \%$ of the deaths caused by these affections concern these countries. It is also the leading cause of physical disability [3]. In sub-Saharan Africa, the incidence is between 26 and 30 per 100,000 inhabitants. The prevalence is around 58 to 243 per 100,000 inhabitants [4]. In the Central African Republic (CAR), strokes represented $8.8 \%$ of patients hospitalized in the Bangui neurology department in 2004 with a one-month mortality rate of $33 \%$ [5]. Stroke is still the disease of the elderly. Although the overall incidence of stroke is decreasing and the rates observed in young adults are increasing, which suggests a need for strategies to improve the situation through prevention [6]. However, in the Central African Republic no specific study has been carried out on the stroke of the young subject. For this, it seemed appropriate to carry out this work, the general objective of which is to contribute to the knowledge of this pathology in young people.

\section{Methodology}

It was a retrospective study with a descriptive and analytical aim which took place over a period of two years from January 2017 to December 2018. We included all patients aged 18 to 49 years, of two sexes hospitalized in the department of neurology of the CHU of the Sino-Central African Friendship of Bangui for cerebrovascular accident whose files were exploitable. Do not part, any subject with stroke aged under 18 or over 49 with incomplete and unusable files. The data were collected from the patient's paper files on pre-established survey sheets and containing socio-demographic data (sex, marital status, profession, origin), History (HTA; diabetes; sickle cell anemia; HIV/AIDS; contraception oral; tobacco), Clinical signs (general condition of the patients; data from the clinical neurological examination; data from the cardiovascular clinical examination), paraclinical signs (renal assessment; lipid assessments, morphological examinations in cardiology) and evolution. The data were entered with Word and Excel software and analyzed with the epi info 3.5.2 software. The chi-square test was used to compare the proportions with a significance level of $5 \%$.

\section{Results}

During this study, 225 cases of stroke were hospitalized, including 26 young subjects, representing a hospital frequency of $11.5 \%$. The average age was 42.5 years with extremes ranging from 24 to 49 years. The most represented age group was that of 45 to 49 years with a sex ratio of $1.36(\mathrm{H} / \mathrm{F})$ (see Table 1). The 
study population was dominated by civil servants $(50 \%)$ followed by traders $19.20 \%$. Unmarried re showed $61.50 \%$ followed seen fs and married (15.40\%).

In our series, almost half (46.2\%) of the patients came from their home, $42.3 \%$ from the CSU/Clinic, $11.5 \%$ from the neurological consultations while $53.8 \%$ arrived in a care structure in the first three hours. The majority of patients $(57.7 \%)$ were admitted to the neurology department after 24 hours following the appearance of the first signs. The main risk factor was alcohol (80.8\%) followed by hypertension (61.5\%) and tobacco (50\%) (Table 2). The main functional signs were motor deficit (80.8\%), headache (65.4\%) and language impairment $(34.6 \%)$. these signs appeared in $38.46 \%$ of cases upon waking. The physical signs were dominated by hemiplegia/hemiparesis (100\%) followed by aphasia (26.9\%) and impairment of consciousness (30.8\%). On the map paraclinical we recorded $73.08 \%$ of DALYs for $57.7 \%$ of $\mathrm{LVH}$, a hype rglycémie in $35.3 \%$ of cases, $29.4 \%$ of anemia and a syndrome biological inflammatory in $25 \%$ of cases. On the evolutionary level, the lethality was $20.08 \%$ of the cases, $69.20 \%$ of the after-effects mainly a hemiparesis and $92.3 \%$ of the patients who spent less than 20 days of hospitalization. During this study, we found that an alertness disorder $(\mathrm{p}<0.01)$ or even coma $(\mathrm{p}<0.01)$ significantly oriented towards AVCH and patients admitted to hospital beyond 6 hours and those with a high initial BP had a higher risk of death (Table 3 ).

Table 1. Distribution of patients and age according to sex and age.

\begin{tabular}{ccc}
\hline Age group & \multicolumn{2}{c}{ Sex } \\
\cline { 2 - 3 } & Male & Female \\
\hline $24-29$ & 0 & 2 \\
$30-34$ & 1 & 1 \\
$35-39$ & 3 & 2 \\
$40-44$ & 7 & 1 \\
$45-49$ & 4 & 5 \\
Total & 15 & 11 \\
\hline
\end{tabular}

Table 2. Distribution of the number of patients according to cardiovascular risk factors.

\begin{tabular}{ccc}
\hline Antecedents & Effective & $(\%)$ \\
\hline HTA & 16 & $61.5 \%$ \\
Diabetes & 4 & $15.4 \%$ \\
Heart disease & 4 & $15.4 \%$ \\
AVC & 3 & $11.5 \%$ \\
Alcohol & 21 & $\mathbf{8 0 . 8 \%}$ \\
Tobacco & 13 & $50.0 \%$ \\
Estrogen plus progestin & 3 & $11.5 \%$ \\
\hline
\end{tabular}


Table 3. Analysis of predictive functional signs of stroke type.

\begin{tabular}{|c|c|c|c|c|c|}
\hline Determinants & DALY & $\mathrm{AVCH}$ & Ratio & $\mathrm{RC}$ and IC & $\mathrm{p}$ \\
\hline Motor deficit & & & & & 0.09 \\
\hline yes & 14 & 7 & $80.8 \%$ & undetermined & \\
\hline No. & 5 & 0 & & 1 & \\
\hline Cephalalgia & & & & & 0.11 \\
\hline yes & 11 & 6 & $65.4 \%$ & $0.24[0.01-2.08]$ & \\
\hline No. & 8 & 1 & & 1 & \\
\hline Language disorder & & & & & 0.31 \\
\hline yes & 6 & 3 & $34.6 \%$ & $0.24[0.10-4.32]$ & \\
\hline No. & 13 & 4 & & 1 & \\
\hline Consciousness disorder & & & & & ${ }^{* *}, 0.01$ \\
\hline yes & 3 & 5 & $30.8 \%$ & $0.09[0.01$ to 0.64$]$ & \\
\hline No. & 16 & 2 & & 1 & \\
\hline Vomiting & & & & & 0.06 \\
\hline yes & 2 & 3 & $19.2 \%$ & $0.17[0.02$ to 1.50$]$ & \\
\hline No. & 17 & 4 & & 1 & \\
\hline Behavior disorder & & & & & 0.26 \\
\hline yes & 3 & 2 & $19.2 \%$ & $0.48[0.06$ to 5.05$]$ & \\
\hline No. & 16 & 5 & & 1 & \\
\hline
\end{tabular}

\section{Discussion}

The prevalence of stroke in the subject during our study was $11.5 \%$. This result is similar to that reported by Lomé in Togo [7]. However, our result is lower than that reported in Douala, Cameroon (15.26\%) in a prospective study conducted over a period of 05 years in subjects aged 15 to 45 years [8]. Likewise Brett et al. were found in a study conducted in Kentucky (eastern USA), the proportion of stroke was increased from $12.9 \%$ in $1993 / 1994$ to $18.6 \%$ in 2005 in subjects from 20 to 54 years [9]. This difference could be explained by better detection of stroke thanks to the generalization of MRI in the USA, and the contribution of $\mathrm{CT}$ in the diagnosis of stroke in Cameroon; whereas in our context, given the inadequacy of the technical platform, certain cases of stroke would be taken for other pathologies. Furthermore, this discrepancy is also linked to the fact that racial and ethnic composition is a widely recognized component in the variability of the incidence of stroke, especially in the young population [10]. In the Central African Republic, we do not have previous data on the prevalence of stroke in young people in order to describe the progression of this pathology. Although the prevalence found during our study is low compared to the data in the literature. We can evoke the epidemiological transition in which the cerebral attack is no longer the prerogative of old age. This corroborates the data of Béjot et al. who have shown that the incidence of stroke in the young population in- 
creases over time [11].

In this study, the average age was 42.5 years with extremes ranging from 24 to 49 years. This result can be superimposed on the data of certain authors in Africa [7] [8] [12], on the other hand lower than that reported in Tunisia [13]. This difference is related to the difference in population size and to the fact that their studies focused only on DALYs. The most represented age group was 45 to 49 years old. Our finding is in line with what he reported by Balogou et al. in Lomé, Togo and These various results corroborate the data in the literature which affirm that although the average age of strokes is gradually getting younger, the frequency of strokes continues to increase with age [14]. A male predominance with an $\mathrm{M} / \mathrm{F}$ sex ratio of 1.36 was found during this study. Our finding is comparable with the various data in the literature [8] [11] [15], but contrary to it found in Tunisia [12]. This discrepancy could arise from the fact that women, in our context, seem to be subject to almost the same risk factors as men. This corroborates certain data from the literature which affirm that the stroke no longer remains the prerogative of the male subject due to the adoption of lifestyle for 30 years by women of the same risky behaviors as men [16] [17]. Beyond the unfavorable development of their lifestyle, women also experience exposure to hormonal factors throughout their lives [18]. Officials were majority 50\%, followed by traders $19.20 \%$. Similar result to that reported in Douala, Cameroon [8]. This strong representation of officials would be linked to the fact that they consult more easily structure scare because of their level of education and income.

Alcohol was the main risk factor (80\%) followed by hypertension (61.5\%) and tobacco (50\%). This high prevalence of alcoholism and smoking could be explained by the change in behavior of the population during the various military-political crises and requires the implementation of awareness-raising strategies and assistance with withdrawal. Our result for alcohol is lower than that reported by Onwuchekwa et al. (27.8\%) in Nigeria [19] and Mapoure et al. (38.46\%) in Cameroon [8]. This discrepancy could be explained by the size of the sample and the duration of the study. In this respect, our results corroborate the data studies by Shinton et al. [20] and a Nigerian series which estimated the proportion of smoking at $50.4 \%$ in the northwest of the country [21]. These studies show that smoking increases the risk of having a stroke, probably in the short term, through prothrombotic effects. Low exposures to tobacco are likely to activate platelet aggregation and cause acute and longer-term hemodynamic changes by promoting the development of atherosclerosis [15]. While hypertension remains the major FDR for strokes with more than $80 \%$ of cases worldwide [8] [21]. In our series, the majority of our patients (57.70\%) arrive at the neurology department after the first 24 hours following the appearance of the first signs. This result is lower than that reported in Togo (70\%) [7]. This difference could be explained by ignorance or even ignorance of the pathology resulting from a delay in orientation in a specialized structure.

Hyperglycemia was found in $35.3 \%$ of cases. This result is almost superim- 
posable on that found in Abidjan [22]. In our series, ischemic stroke represented $73.08 \%$ of the cases. This result is identical to the data in the literature [7] [23]; however the prevalence of ischemic strokes compared to hemorrhagic strokes tends to decrease more and more or oven to reverse since the advent of imaging by CT Scan in Africa [8] [23].

Lethality was $20.08 \%$ of cases. This result is similar to the data reported in Togo [7], superimposed on that reported (23.9\%) in Nigeria [21]. On the other hand, it is lower than the data for Cameroun and Nigeria. In addition, in the United States, 30-day mortality is low and estimated at 17\% [8]. This difference is linked to the quality of the PEC in the acute phase of the brain attack and to a better organization of the health system unlike in Africa. In our series, $69.20 \%$ of patients left with sequelae dominated by hemiparesis $(72.20 \%)$ followed by a dysarthria-type language disorder in $22.20 \%$. Our result corroborates certain data from the literature which affirm that $30 \%$ to $50 \%$ of young patients, victims of stroke, cannot resume their professional activity and nearly $10 \%$ remain dependent for at least one activity of daily life [24] [25]. This study allowed us to identify a link between the type of stroke and the state of consciousness on admission or physical examination. Patients admitted with a consciousness disorder are more likely to have a stroke than a stroke. Our observation joins the literature which affirms that in the AVCH the disorder of the conscience is precocious [26].

It emerges from this study that the delay in admission to the first structure of care and BP have a positive influence on intra-hospital mortality. This finding partly overlaps with what had been reported in Cameroon [8] that hypertension was among the predictive factors associated with intrahospital death whereas the time for admission was not. Could this discrepancy on the time of admission be linked to the initial PEC or to a difficulty in the patient referral system? Because the management of stroke in the acute phase remains codified, its ignorance could have repercussions on the life prognosis of patients. Thus, the quality of the initial PEC in non-specialized structures would have a negative impact on the evolutionary prognosis of our patients, especially by the fact that in stroke, the increase in BP is physiological and contributes to lengthening the period of penumbra ischemic [27] [28]. Besides the difficulty on the question of referral of patients, some authors in the Central African Republic had reported that the reason for the lengthening of the admission period is also explained by the mentality of our community, which first seeks to link the phenomena of sudden appearance to a supernatural cause. This may testify to the ignorance of the population regarding this condition. This calls into question the need to carry out awareness-raising activities in order to enlighten the population in order to reduce the harmful consequences that may result from it [29].

\section{Conclusion}

Stroke is a public health problem with dramatic functional and life-threatening consequences. Long considered the disease of the elderly, its incidence is clearly 
increasing in the young population in both sexes due to risky behaviors such as the consumption of alcohol and tobacco observed in this group of population. Improving the treatment of stroke for young people in the Central African Republic involves, on the one hand, the participation of health professionals in the quality of adequate and appropriate PEC and of the political and health authorities in raising the technical level of diagnosis, and secondly responsible behavior of patients and their carers.

\section{Conflicts of Interest}

The authors declare no conflicts of interest regarding the publication of this paper.

\section{References}

[1] Bouleti, C., Mathivet, T., Lapergue, B., Monnot, C. and Germain, S. (2014) Cerebrovascular Accident: Protection of Vascular Integrity during Reperfusion. Médicine Sciences, 30, 609-608. https://doi.org/10.1051/medsci/20143006003

[2] Strong, K., Mathers, C. and Bonita, R. (2007) Preventing Stroke: Saving Lives around the World. The Lancet, 6, 182-187. https://doi.org/10.1016/S1474-4422(07)70031-5

[3] Da Kouakou N Goran, Y.N., Traore, F., Tano, M., Kramoh, K.E., et al. (2015) Epidemiological Aspects of Cerebrovascular Accidents in the Emergency Room of the Abidjan Heart Institute. The Pan African Medical Journal, 21, 160.

[4] Belo, M., Balogou, A.A.K., Goeh-Akue, E., et al. (2007) Peculiarities of Strokes in Togo and Black Africa. Journal of Scientific Research of the University of Lomé, 9 , 125-129.

[5] Mbelesso, P., Tabo, A., Seboulo, P.C., Yangatimbi, E., Kette, C.G. and Senekian. V.P. (2007) Epidemiological Aspects of Strokes at the Bangui Hospital in the Central African Republic. Benin Medical, 37, 44-46.

[6] Béjot, Y., Bailly, H., Durier, J. and Giroud, M. (2016) Epidemiology of Stroke in Europe and Trends for the 21st Century. La Presse Médicale, 45, 391-398.

https://doi.org/10.1016/j.lpm.2016.10.003

[7] Balogou, A.A.K., Grunitzky, E.K. and Assogba, K. (2008) Stroke in Young Subjects (15-45 Years Old) in the Neurology Department of the Lomé Campus Hospital. African Journal of Neurological Sciences, 27, 44-51. https://doi.org/10.4314/ajns.v27i2.55090

[8] Mapoure, Y., Essissima, M.F., Ba, H., et al. (2016) Spectrum of Cerebrovascular Diseases in Young Subjects in Douala. The Pan African Medical Journal, 23, Article 250. https://doi.org/10.11604/pamj.2016.23.250.7102

[9] Kissela, B.M., Khoury, J.C., Alwell, K., et al. (2012) Age at Stroke: Temporal Trends in Stroke Incidence in a Large, Biracial Population. Neurology, 79, 1781-1787. https://doi.org/10.1212/WNL.0b013e318270401d

[10] Smajlovic, D. (2015) Stroke in Young Adults: Epidemiology and Prevention. Vascular Health and Risk Management, 11, 157-164. https://doi.org/10.2147/VHRM.S53203

[11] Béjot, Y., Legris, N., Daumas, A., et al. (2016) Stroke in the Young Person: An Emerging Pathology in Women as in Men. Contributions from the Dijon Registry of Strokes (1985-2011). Bulletin Épidémiologique Hebdomadaire, No. 7-8, 118-125. 
[12] Zakhama, L., Ksontini, I., Boussabah, E., Bechichi, W. and Benyoussef, S. (2008) Strokes in the Young Subject. La Revue de Médecine Interne, 29, S77. https://doi.org/10.1016/j.revmed.2008.03.137

[13] Khammassi, N., Sassi, Y.B., Aloui, A., Kort, Y., Abdelhedi, H. and Cherif, O. (2015) Ischemic Stroke in Young People: About 6 Cases. The Pan African Medical Journal, 22, Article 142. https://doi.org/10.11604/pamj.2015.22.142.7609

[14] WHO (1989) Task Force on Stroke and Other Cerebrovascular Disorders. WHO, Geneva, $53 \mathrm{p}$.

[15] Béjot, Y., Touzé, E., Jacquin, A., Giroud, M. and Mas, J.L. (2009) Epidemiology of Stroke. Médicine Sciences, 25, 727-732. https://doi.org/10.1051/medsci/2009258-9727

[16] Mosca, L., Benjamin, E.J., Berra, K., et al. (2011) Effectiveness-Based Guidelines for the Prevention of Cardiovascular Disease in Women-2011 Update: A Guideline from the American Heart Association. Circulation, 123, 1243-1262. https://doi.org/10.1161/CIR.0b013e31820faaf8

[17] Aouba, A., Eb, M., Rey, G., Pavillon, G. and Jougla, E. (2011) Data on Mortality in France: Main Causes of Death in 2008 and Trends since 2000. Bulletin Épidémiologique Hebdomadaire, No. 22, 249-255.

[18] Bushnell, C., Mccullough, L.D., Awad, I.A., et al. (2014) American Heart Association Stroke Council; Council on Cardiovascular and Stroke Nursing; Council on Clinical Cardiology; Council on Epidemiology and Prevention; Council for High Blood Pressure Research. Guidelines for the Prevention of Stroke in Women: A Statement for Healthcare Professionals from the American Heart Association/American Stroke Association. Stroke, 45, 1545-1588.

[19] Onwuchekwa, A.C., Onwuchekwa, R.C. and Asekomeh, A.G. (2009) Stroke in Young Nigerian Adults. Journal of Vascular and Interventional Neurology, 27, 98-102. https://doi.org/10.1016/j.jvn.2009.08.001

[20] Shinton, R., Beevers, G., Gill, G.S. and Zezulk, A.V. (1989) Meta-Analysis of Relation between Cigarette Smoking and Stroke. BMJ, 298, 789-794. https://doi.org/10.1136/bmj.298.6676.789

[21] Owolabi, L.F. and Ibrahim, A. (2012) Stroke in the Young Adult: A Prospective Study from Northwestern Nigeria. International Scholarly Research Notices, 2012, Article ID: 468706. https://doi.org/10.5402/2012/468706

[22] Kouame, A.B., Assouan, A.E., Million, D.-O., Abodo, J.R. and Sunan Douayoua, T. (2015) Particularities of Strokes in Diabetics. AJNS, 34.

[23] Toure, K., Kane, M., Kane, A., Tal, D.A., Ndiaye, M.M. and Ndiaye, I.P. (2010) Contribution of Computed Tomography in the Epidemiology of Cerebrovascular Accidents at the Grand Yoff General Hospital. Black African Medicine, 57, 455-460.

[24] Varona, J.F. (2010) Long-Term Prognosis of Ischemic Stroke in Young Adults. Stroke Research and Treatment, 2011, Article ID: 87981. https://doi.org/10.4061/2011/879817

[25] Schnitzler, A., Woimant, F., Tuppin, P. and De Peretti, C. (2014) Prevalence of Self-Reported Stroke and Disability in the French Adult Population: A Transversal Study. PLoS ONE, 9, e115375.

[26] Community Immersion (2009) Strokes, 70.

[27] Goupil, A., Bourghol, B., Derouet, N., Savio, C. and Bourrier, P. (2002) Management of Ischemic Stroke in Young Patients in an Emergency: Etiological and Therapeutic Aspects. Réanimation, 11, 502-508.

https://doi.org/10.1016/S1624-0693(02)00286-4 
[28] Milhaud, D., Blard, J.M. and Pages, M. (2001) Neurological Emergencies. Masson Paris: $395 \mathrm{P}$

[29] Mbelesso, P., Yangatimbi, E. and Senekian, V.P. (2018) Prognostic Factor Associated With Mortality Related to Stroke in Bangui (Central African Republic). Neuroscience \& Medicine, 9, 198-208. https://doi.org/10.4236/nm.2018.94020 